\title{
COMPARISON OF VISUAL OUTCOMES OF DEEP ANTERIOR LAMELLAR KERATOPLASTY AND PENETRATING KERATOPLASTY
}

\author{
Rajesh Goel1 ${ }^{1}$ Akshi Agarwal², J. K. Chouhan ${ }^{3}$, Pankaj Sharma4, Dharmesh Sharma 5 \\ ${ }^{1}$ Assistant Professor, Department of Ophthalmology, SMS Medical College \& Hospital, Jaipur. \\ ${ }^{2}$ Assistant Professor, Department of Obstetrics \& Gynaecology, SMS Medical College, Jaipur. \\ 3 Professor and HOD, Department of Ophthalmology, SMS Medical College \& Hospital, Jaipur. \\ ${ }^{4}$ Professor, Department of Ophthalmology, SMS Medical College \& Hospital, Jaipur. \\ ${ }^{5}$ Assistant Professor, Department of PSM, SMS Medical College \& Hospital, Jaipur.
}

\section{ABSTRACT}

\section{BACKGROUND}

Deep Anterior Lamellar Keratoplasty (DALK) has been used as an alternative to PK in the last few years in cases with intact endothelium, such as stromal scar, stromal dystrophies, and keratoconus. This surgical technique conserves the patient's own endothelial cells. The present study was conducted with an aim to compare the visual outcome and various complications of Deep Anterior Lamellar Keratoplasty (DALK) and Penetrating Keratoplasty (PK).

\section{MATERIALS AND METHODS}

A non-randomised controlled trial of 80 cases in which either Deep Anterior Lamellar Keratoplasty (DALK) or Penetrating keratoplasty (PK) done from January 2013 to January 2016, was conducted at SMS Medical College \& Hospital, Jaipur. The main outcomes measured were visual outcome, graft survival and complications.

\section{RESULTS}

There were not much differences between PK and DALK groups in terms of age and gender. Preoperative visual acuity in both the groups was less than 3/60. There was no significant difference between PK and DALK groups in terms of the postoperative BCVA at 1 year. BCVA was $6 / 24$ or better in $44.73 \%$ cases in DALK group and in $40 \%$ cases in PK group. Postoperative complications were significantly more frequent after PK.

\section{CONCLUSION}

Visual returns of Deep Anterior lamellar Keratoplasty are comparable to that of Penetrating keratoplasty (PK) with less complications. Although the learning curve is a bit steep but being an extraocular procedure with preservation of host endothelium, it is a major advantage over Penetrating keratoplasty (PK).

\section{KEYWORDS}

Deep Anterior Lamellar Keratoplasty (DALK), Penetrating Keratoplasty (PK).

HOW TO CITE THIS ARTICLE: Goel R, Agarwal A, Chouhan JK, et al. Comparison of visual outcomes of deep anterior lamellar keratoplasty and penetrating keratoplasty. J. Evolution Med. Dent. Sci. 2017;6(71):5027-5030, DOI: 10.14260/Jemds/2017/1093

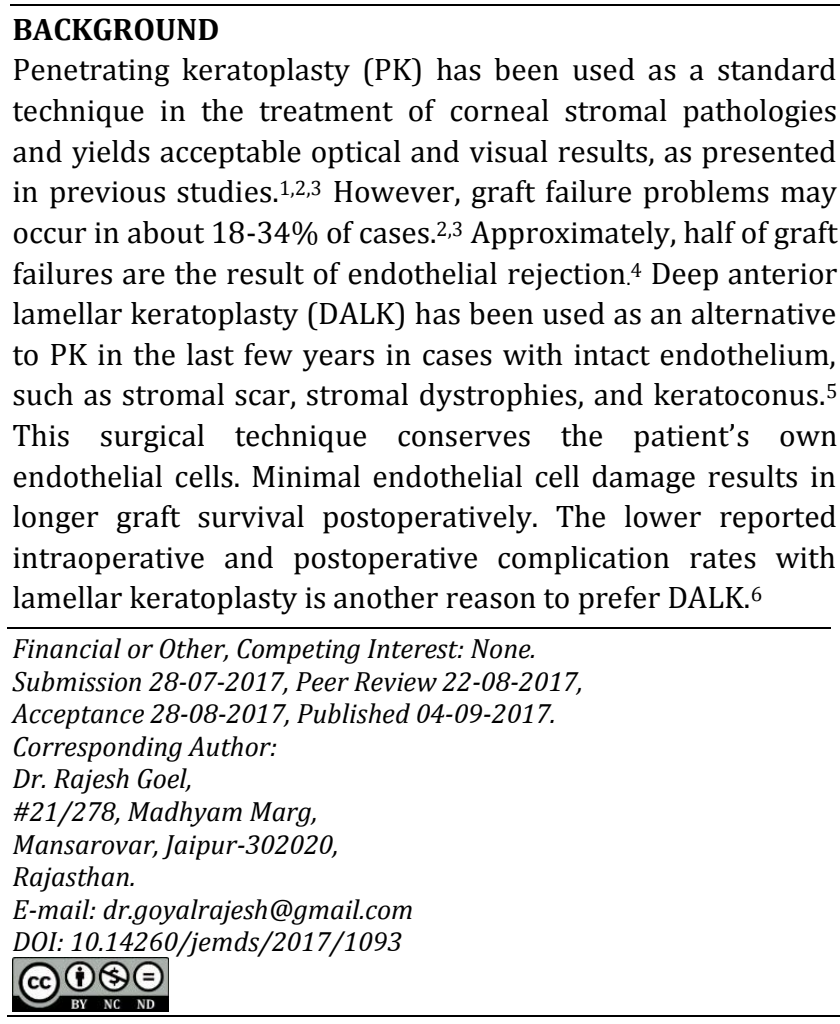
However, intraoperative complication rates may be slightly higher in the early stages of the DALK procedure. Furthermore, the procedure has a long learning curve, is laborious and has a longer surgery duration.

The basic principle of lamellar keratoplasty is to replace only that part of cornea that is diseased and leave the recipient's normal anatomic layers intact. The idea is to do the least amount of resection with greatest amount of benefit thus leaving the healthy endothelium and Descemet's membrane as an immunological barrier to the rejection.

\section{Current techniques ${ }^{7,8,9}$ of Deep Anterior Lamellar Keratoplasty (DALK) are of Two Types}

1. Deep stromal dissection achieved manually, microkeratome assisted or using femtosecond laser. A variable amount of stroma is left behind, therefore the interface between donor and recipient is intrastromal. Stroma to stroma interface may impede visual acuity by optical interference.

2. Big Bubble technique- Refers to injection of air deep into the stroma generating a big air bubble between stroma \& the Descemet's membrane, thus causing a large detachment of Descemet's Membrane without using a surgical instrument. This provides safe, speedy \& consistent exposure of the smooth \& shinning surface of 
Descemet's membrane. On the donor side, Descemet's membrane is peeled off by the non-toothed forceps resulting in another uniform \& smooth surface. The apposition of donor button to the bare Descemet's membrane provide an interface of high quality. The procedure is standardised because the interface achieved is exactly the same in every case.

The present study was conducted with an aim to compare the visual outcome and various complications of Deep Anterior Lamellar Keratoplasty (DALK) and Penetrating keratoplasty (PK).

\section{MATERIALS AND METHODS \\ Design \& Sampling \\ Design}

Non-randomised controlled trial.

\section{Study Period}

January 2013 to January 2016.

\section{Sampling}

Patients who were following the inclusion criteria according to our study during the study period at SMS Medical College \& Hospital, Jaipur were included in the study.

\section{Sampling Procedure and Justification of sampling size}

In the study period, 80 cases were according to the inclusion criteria and were operated during the study period; so we have 80 cases in the study. Consecutive patients were alternately selected to receive one of the two surgical methods. So, 40 cases were of Deep Anterior Lamellar Keratoplasty (DALK) by Big Bubble technique and their results were compared with 40 cases of penetrating Keratoplasty. All the cases were done by the same surgeon.

\section{Ethical Issues}

The study followed the tenets of the Declaration of Helsinki and had local Ethical Committee approval. An informed consent was obtained from all participants.

\section{Inclusion Criteria}

Keratoconus, Keratoglobus, Pellucid marginal degeneration, keratectasia following refractive surgery, Stromal opacities/scars sparing Descemet's membrane and Corneal dystrophies involving anterior/deep stroma.

\section{Exclusion Criteria}

Corneal conditions with diseased endothelium, pre-existing rupture in Descemet's membrane, Deep scars involving Descemet's membrane, any pre-existing posterior segment pathology and any significant ocular surface abnormality (severe dry eye, Limbal Stem Cell Deficiency)

A non-randomised controlled trial of 80 cases in which either Deep Anterior Lamellar Keratoplasty (DALK) or Penetrating keratoplasty (PK); done between January 2013 to January 2016; was conducted at SMS Medical College \& Hospital, Jaipur. The main outcome measured were visual outcome, graft survival and complications.

As per records patients underwent an ophthalmic examination weekly in $1^{\text {st }}$ month, biweekly in $2^{\text {nd }}$ month and then monthly till 12 months postoperatively. Ocular examinations included evaluation of Snellen best spectacle corrected visual acuity (BCVA), biomicroscopy of the anterior segment, intraocular pressure (IOP) measurement with Goldmann applanation tonometer or Tonopen, and fundus examination.

Minimum postoperative follow-up was 12 months. Drop outs from follow-up were excluded. Main outcome measured was BCVA at 1 year. Secondary outcome measured were immune rejection, graft clarity, IOP, intraoperative and postoperative complications.

\section{Procedure followed for $\mathrm{PK}$}

Full thickness donor graft was sutured by 16 interrupted 10 0 nylon monofilament sutures to the host.

\section{Procedure followed for DALK}

A detailed history and clinical examination of the eye was done. Routine preoperative investigations were ordered. Deep Anterior Lamellar Keratoplasty (DALK) by Big Bubble technique was carried out-

- Intravenous mannitol (1-1.5 mg/kg body weight) was given preoperatively.

- Peribulbar anaesthesia was given in cooperative patients. In uncooperative patients and children general anaesthesia was given.

- By using Suction Trephine 420 Micron groove was made in the host cornea.

- A partial thickness removal of anterior stroma was done by using crescent knife.

- After making a small incision in the stroma, a blunt tipped probe was introduced in deep stroma. DALK cannula with inferior opening was used to achieve injection of air in the deep stroma resulting in formation of big bubble (Figure 1) between stroma and the Descemet's membrane.

- Trifacet probe was introduced into the deep stromal layers and a sharp blade was used to dissect the remaining stromal layer in two cruciate incisions.

- Removal of stroma (Figure 2) was achieved using directional scissors.

Peeling of endothelium from the donor cornea was done after taking the appropriate-sized endothelial punch.

- Suturing of donor cornea over the Bare Descemet's membrane of the host (Figure -3) was done by 16 interrupted 10-0 nylon monofilament sutures.

- Drop of antibiotic-steroid with cycloplegic instilled and eye was patched for $24 \mathrm{hrs}$.

- Topical steroid-antibiotic combination was used in tapering doses till 3-6 months, following which it was used as and when condition demanded.

- Cycloplegics were withdrawn after 2 weeks. Topical lubricants were continued in all cases till last followup.

2 cases had ruptured Descemet's membrane during different stages of surgery and had to be converted to Penetrating keratoplasty (PK) and excluded from study.

\section{Statistical Analysis}

Statistical analysis was performed using primer software. Comparison among groups was performed using Chi-square test and independent samples test. $\mathrm{P}$ values $<0.05$ were considered to be significant. 


\section{RESULTS}

- There were not much differences between PK and DALK groups in terms of age and gender. (Table 1).

- Preoperative visual acuity in both the groups was less than 3/60. (Table 2).

- There was no significant difference between PK and DALK groups in terms of the postoperative BCVA at $1 \mathrm{yr}$. BCVA was $6 / 24$ or better in $44.73 \%$ cases in DALK group and in $40 \%$ cases in PK group. (Table 3 ).

Postoperative complications were significantly more frequent after PK. (Table 4). IOP elevations occurred in 25 cases with PK and 2 cases with DALK and were controlled with brimonidine or its fixed combination with timolol. A fixed dilated pupil occurred in 1 eye due to prolonged use of Homatropine after the operation in PK. Endothelial rejection episodes occurred in 5 eyes in PK. They were treated with intravenous pulsed methylprednisolone $500 \mathrm{mg}$ for three days followed by oral route. Grafts cleared after the treatment. No rejection episode was observed in 38 DALKoperated eyes. Postoperative double anterior chamber occurred in 1 eye with microperforation in DALK group. It was successfully managed with air injection into the anterior chamber.

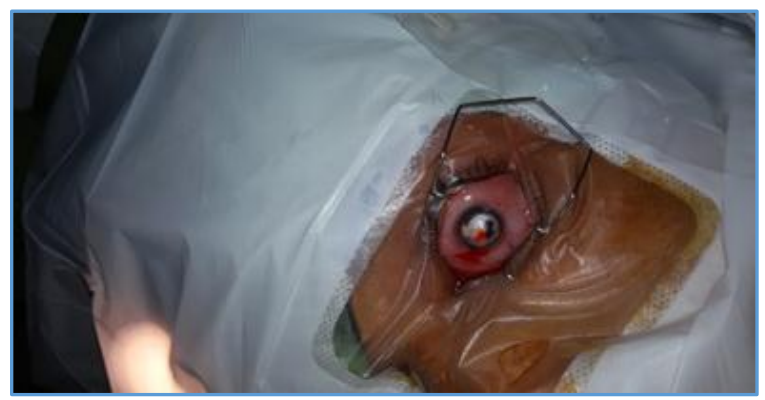

Figure 1. Big Bubble Formed

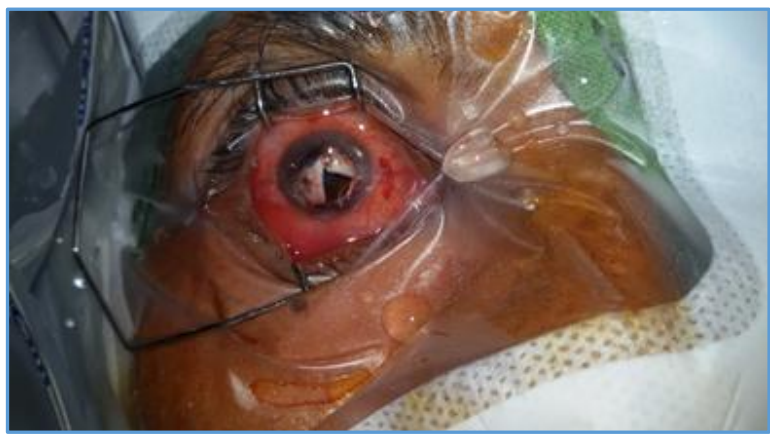

Figure 2. Removal of Stroma

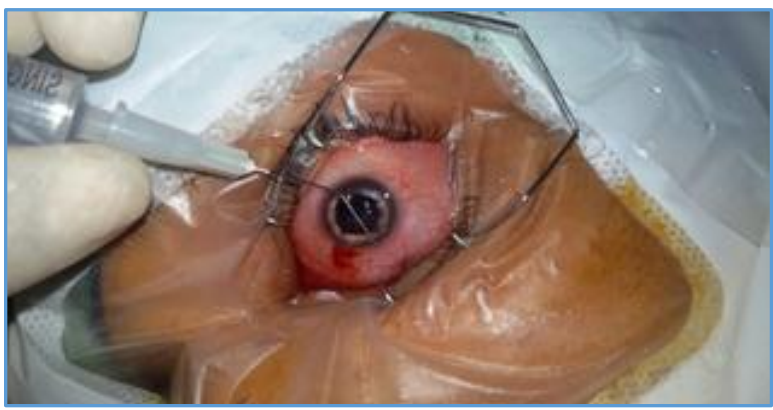

Figure 3. Bare Endothelium and Descemet's Membrane of Host

\begin{tabular}{|c|c|c|c|}
\hline Sl. No. & Parameter & PK (n=40) & DALK (n=38) \\
\hline 1. & AGE (years) (mean) & 48.2 yrs. & 45.6 yrs. \\
\hline 2. & Sex (Male/Female) & $22 / 18$ & $20 / 18$ \\
\hline 3. & Eyes (Right/Left) & $28 / 12$ & $24 / 14$ \\
\hline \multicolumn{4}{|c|}{ Table 1. Comparison of Demographic Features } \\
of PK \& DALK Group \\
\hline
\end{tabular}

PK - Penetrating Keratoplasty

DALK - Deep Anterior Lamellar Keratoplasty.

\begin{tabular}{|c|c|c|c|}
\hline Sl. No. & $\begin{array}{c}\text { Preoperative } \\
\text { Visual Acuity }\end{array}$ & PK (n=40) & DALK (n=38) \\
\hline 1. & PL+ PR Accurate & $25(62.5 \%)$ & $23(60.5 \%)$ \\
\hline 2. & $1 / 60$ to $3 / 60$ & $15(37.5 \%)$ & $15(39.47 \%)$ \\
\hline
\end{tabular}

Table 2. Comparison of Preoperative Visual Acuity in PK \& DALK Group

$P$ value -0.957 (non-significant)

PK - Penetrating Keratoplasty

DALK - Deep Anterior Lamellar Keratoplasty

\begin{tabular}{|c|c|c|c|}
\hline $\begin{array}{c}\text { Sl. } \\
\text { No. }\end{array}$ & $\begin{array}{c}\text { Postoperative } \\
\text { (BCVA) at 1 yr. }\end{array}$ & $\begin{array}{c}\text { PK } \\
\text { (Cases)(n=40) }\end{array}$ & $\begin{array}{c}\text { DALK (Cases) } \\
\text { (n=38) }\end{array}$ \\
\hline 1. & $1 / 60$ to $3 / 60$ & 4 & 4 \\
\hline 2. & $4 / 60$ to $6 / 60$ & 10 & 6 \\
\hline 3. & $6 / 60$ to $6 / 36$ & 10 & 11 \\
\hline 4. & $6 / 24$ or better & 16 & 17 \\
\hline \multicolumn{3}{|c|}{ Table 3. Comparison of Postoperative BCVA in } \\
PK \& DALK Group \\
\hline
\end{tabular}

$P$ value 1.00 (non-significant)

PK - Penetrating Keratoplasty

DALK - Deep Anterior Lamellar Keratoplasty

BCVA-Best Corrected Visual Acuity

\begin{tabular}{|c|c|c|c|}
\hline Sl. No. & Complications & PK & DALK \\
\hline 1. & IOP elevation & 25 & 2 \\
\hline 2. & Rejection Episode & 5 & 0 \\
\hline 3. & Suture loosening & 4 & 1 \\
\hline 4. & Dilated pupil & 1 & 0 \\
\hline 5. & $\begin{array}{c}\text { Double anterior } \\
\text { chamber }\end{array}$ & 0 & 1 \\
\hline \multicolumn{3}{|c|}{ Table 4. Postoperative Complications } \\
\hline
\end{tabular}

$P$ value - 0.03 (less than 0.05 - Significant)

PK - Penetrating Keratoplasty

DALK - Deep Anterior Lamellar Keratoplasty

\section{DISCUSSION}

In this study, BCVA at 12 months was similar in PK group and DALK group. This similarity may be because 16 interrupted sutures are placed in both PK \& DALK. Our results are comparable to other studies as Akdemir et al ${ }^{10}$ reported mean BCVA at 1 yr. $0.15 \operatorname{logMAR}$ for DALK and 0.21 for PK without a statistical significance. Donoso et $\mathrm{al}^{11}$ reported 0.17 for both surgeries. Smadja et al ${ }^{12}$ reported a logMAR BCVA of 0.88 for DALK at 12 months.

In our DALK surgeries, intraoperative DM perforation occurred in $5.2 \%$ cases and converted to PK. DM perforation rate has been reported between $4.0 \%-39.2 \%$ and large DM tears needing conversion to PK between $2.3 \%-27.3 \%$ in the literature. ${ }^{13,14}$ Our rates are consistent with these reports.

Formation of type 2 bubble during air injection is associated with high perforation rate. ${ }^{15}$ 
In our study, postoperative complications are reported more frequently after PK compared to DALK and it is comparable to $31.8 \%$ vs. $4.5 \%$ in another study. ${ }^{16}$

This may be because DALK is essentially an extraocular procedure so there are less chances of complications in DALK as compared to $\mathrm{PK}$.

IOP elevation occurred in $62.5 \%$ of PK and $5.26 \%$ of DALK eyes in our study. This finding is consistent with previous report of $46.2 \%$ vs. $1.3 \% .13$ It is likely to be a consequence of the use of steroid drops for shorter period and lower intensity after DALK.

Endothelial rejection episodes were observed in $12.5 \%$ of our PK cases. Cohen et al ${ }^{17}$ reported this rate as $13.3 \%$ for PK and Donoso et al ${ }^{11}$ as $8 \%$. Zhang et al ${ }^{13}$ reported $7.7 \%$ allograft rejection. This may be because most common cause of rejection is endothelium and endothelium is not transplanted in DALK while full thickness transplantation is carried out in PK. Although stromal rejection episodes have been reported in $1.7 \%$ to $11.3 \%$ within 4 yrs., no rejection episode was observed in our DALK cases. ${ }^{14,18}$ The median predicted survival was reported as $49.0 \mathrm{yrs}$. in DALK and 17.3 yrs. in PK. ${ }^{19}$

Reported annual endothelial cell loss rates of $14.1 \%$ in PK and $5.8 \%$ in DALK are much higher than physiologic loss of $0.6 \%$ per year. ${ }^{20,21}$ It suggests that the removal of stroma and exposure of DM may lead to endothelial cell loss due to indirect trauma.

The limitations of this study include small sample size and relatively short follow-up.

\section{CONCLUSION}

The big bubble technique allows safe and consistent exposure of Descemet's membrane. There are minimal chances of endothelial cell damage, a distinctive advantage over penetrating keratoplasty. The procedure is essentially extraocular and minimises the risk of endophthalmitis. Minimum use of postoperative steroids reduces steroidinduced complications.

Thus, visual returns of Deep Anterior Lamellar Keratoplasty are comparable to that of Penetrating keratoplasty (PK) with less complications. Although the learning curve is a bit steep but being an extraocular procedure with preservation of host endothelium, it is a major advantage over Penetrating keratoplasty (PK).

\section{REFERENCES}

[1] Javadi MA, Motlagh BF, Jafarinasab MR, et al. Outcomes of penetrating keratoplasty in keratoconus. Cornea 2005;24(8):941-6.

[2] Beckingsale $\mathrm{P}$, Mavrikakis I, Al-Yousuf $\mathrm{N}$, et al. Penetrating keratoplasty: outcomes from a corneal unit compared to national data. Br J Ophthalmol 2006;90(6):728-31.

[3] Thompson RW, Price MO, Bowers PJ, et al. Long-term graft survival after penetrating keratoplasty. Ophthalmology 2003;110(7):1396-402.

[4] Patel SV, Hodge DO, Bourne WM. Corneal endothelium and postoperative outcomes 15 years after penetrating keratoplasty. Am J Ophthalmol 2005;139(2):311-9.

[5] Reinhart WJ, Musch DC, Jacobs DS, et al. Deep anterior lamellar keratoplasty as an alternative to penetrating keratoplasty: a report by American academy of ophthalmology. Ophthalmology 2011;118(1):209-18.

[6] Tan DT, Mehta JS. Future directions in lamellar corneal transplantation. Cornea 2007;26(9 Suppl 1):S21-8.

[7] Soong HK, Farjo AA, Katz D, et al. Lamellar corneal patch grafts in the management of corneal melting. Cornea 2000;19(2):126-34.

[8] Kremer I, Sperber LTD, Laibson PR, et al. Pellucid marginal degeneration treated by lamellar \& penetrating keratoplasty. Arch Ophth 1993;111(2):169-70.

[9] Fronterre A, Portesani GP. Epikeratoplasty for pellucid marginal degeneration. Cornea 1991;10;450-3.

[10] Akdemir MO, Kandemir B, Sayman IB, et al. Comparison of contrast sensitivity and visual acuity between deep anterior lamellar keratoplasty and penetrating keratoplasty in patients with keratoconus. Int J Ophthalmol 2012;5(6):737-41.

[11] Donoso R, Díaz C, Villavicencio P. Comparative study of keratoconus between Anwar's deep anterior lamellar keratoplasty versus converted penetrating keratoplasty. Arch Soc Esp Oftalmol 2015;90(6):25763.

[12] Smadja D, Colin J, Krueger RR, et al. Outcomes of deep anterior lamellar keratoplasty for keratoconus: learning curve and advantages of the big bubble technique. Cornea 2012;31(8):859-63.

[13] Zhang YM, Wu SQ, Yao YF. Long-term comparison of full-bed deep anterior lamellar keratoplasty and penetrating keratoplasty in treating keratoconus. J Zhejiang Univ Sci B 2013;14(5):438-50.

[14] Kubaloglu A, Sari ES, Unal M, et al. Long-term results of deep anterior lamellar keratoplasty for the treatment of keratoconus. Am J Ophthalmol 2011;151(5):760-7.

[15] Goweida MB. Intraoperative review of different bubble types formed during pneumodissection (big-bubble) deep anterior lamellar keratoplasty. Cornea 2015;34(6):621-4.

[16] MacIntyre R, Chow SP, Chan E, et al. Long-term outcomes of deep anterior lamellar keratoplasty versus penetrating keratoplasty in Australian keratoconus patients. Cornea 2014;33(1):6-9.

[17] Cohen AW, Goins KM, Sutphin JE, et al. Penetrating keratoplasty versus deep anterior lamellar keratoplasty for the treatment of keratoconus. Int Ophthalmol 2010;30(6):675-81.

[18] Romano V, Iovieno A, Parente G, et al. Long-term clinical outcomes of deep anterior lamellar keratoplasty in patients with keratoconus. Am J Ophthalmol 2015;159(3):505-11.

[19] Borderie VM, Sandali O, Bullet J, et al. Long-term results of deep anterior lamellar versus penetrating keratoplasty. Ophthalmology 2012;119(2):249-55.

[20] Kubaloglu A, Koytak A, Sari ES, et al. Corneal endothelium after deep anterior lamellar keratoplasty and penetrating keratoplasty for keratoconus: a fouryear comparative study. Indian J Ophthalmol 2012;60(1):35-40.

[21] Bourne WM, Nelson LR, Hodge DO. Central corneal endothelial cell changes over a ten-year period. Invest Ophthalmol Vis Sci 1997;38(3):779-82. 